\title{
A Green Method for the Enhancement of Antifungal Properties of Various Textiles Functionalized with Silver Nanoparticles
}

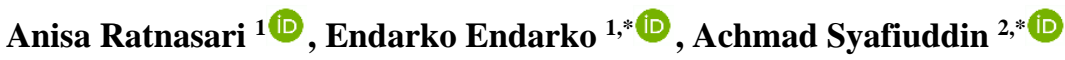 \\ 1 Department of Physics, Institut Teknologi Sepuluh Nopember, 60111 Surabaya, East Java, Indonesia \\ 2 Department of Water and Environmental Engineering, Faculty of Engineering, Universiti Teknologi Malaysia, 81310 \\ UTM Johor Bahru, Johor, Malaysia \\ * Correspondence: endarko@gmail.com (E.E.); ac.syafi@gmail.com (A.S.);
}

Scopus Author ID 55217620100 (E.E.); 56682128000 (A.S.)

Received: 10.05.2020; Revised: 3.06.2020; Accepted: 5.06.2020; Published: 8.06.2020

\begin{abstract}
Development of textiles functionalized with nanoparticles has received growing interest. A wide range of nanoparticles can be deposited on textile fibers, which brings new properties to the final product. Although many methods for the deposition of silver nanoparticles (AgNPs) on textiles are possible, the current trend focuses on how this can be carried out in a cheaper and greener manner. Therefore, the present study aims to propose a green method for the enhancement of antifungal of textiles using AgNPs. Textile properties such as surface morphology, elemental contents, density, water absorption, and antifungal capability were comprehensively characterized. This study found that the deposition of AgNPs on the textiles can be successfully carried out using the proposed method, confirmed by the field emission scanning electron microscopy (FESEM) and energy-dispersive X-ray spectroscopy (EDX) inspections. The water absorption capability of the treated textiles was lower compared to untreated textiles. In addition, the effective antifungal capability of the treated textiles has been approved, although after 5 washing cycles.
\end{abstract}

Keywords: Silver nanoparticles; antifungal properties; functionalized textiles; green method.

(C) 2020 by the authors. This article is an open-access article distributed under the terms and conditions of the Creative Commons Attribution (CC BY) license (https://creativecommons.org/licenses/by/4.0/).

\section{Introduction}

Silver nanoparticles (AgNPs) have earned enormous popularity in scientific literature due to their exclusive and desirable physical, chemical, and biological properties [1-7]. Several industries employed AgNPs for their final products, such as cosmetics, detergents, paint industries, and textiles. For medical and textile industries, AgNPs are used to inhibit the growth of bacteria and fungi.

Several methods have been proposed for the synthesis of AgNPs, such as by chemical, physical, and biological methods [8]. Chemical and physical methods have limitations such as the use of toxic chemicals that are potential to be released into the environment and high energy consumption, respectively. Therefore, the biological or green method seems to be a safe procedure since it provides several advantages such as simple procedures for preparation, the use of non-toxic materials, and environmentally friendly $[9,10]$. In green synthesis, natural reducing and stabilizing agents are used to reduce $\mathrm{Ag}^{+}$to $\mathrm{Ag}^{0}$ and to prevent agglomeration, respectively $[11,12]$. 
Recently, there has been tremendous research interest in the functionalization of textiles using AgNPs with the aim to produce fabrics with diverse practical performance. Due to their remarkable surface plasmon resonance feature, AgNPs have also been applied as novel and new generation colorants for various textile products. Numerous procedures for the deposition of AgNPs on textiles have been proposed and still continuously revised. They include solutionimmersion, layer-by-layer deposition, and sonochemical procedures. For instance, AgNPs were formed on the cotton fabric surface using the solution-immersion by pre-activation by potassium hydroxide and in situ reductions of silver nitrate $\left(\mathrm{AgNO}_{3}\right)$ [13]. The treated cotton showed high antibacterial activity against Gram-positive Staphylococcus aureus and Gramnegative Escherichia coli. In addition, nylon and silk fibers were employed to fabricate antimicrobial textiles enhanced using AgNPs prepared by the layer-by-layer deposition method [14]. The study successfully achieved $80 \%$ and $50 \%$ bacteria (Staphylococcus aureus) reduction for the silk and the nylon fibers, respectively. Moreover, the sonochemical coating of AgNPs on various textile fabrics, namely, nylon, polyester, and cotton, can also be an alternative method [15]. The successful method exhibited excellent antibacterial activity against Staphylococcus aureus and Escherichia coli, depending on the textiles type.

It is noted that the solution-immersion method provides a simple procedure for the deposition of AgNPs on textiles compared to others. In addition, the solution-immersion method can potentially diminish the use of high energy consumption, which is difficult to achieve when the layer-by-layer deposition and sonochemical are used. Currently, a green method based on plant biomolecule-mediated in-situ synthesis seems a viable option for the deposition of AgNPs onto textile surfaces. In this method, biomolecules present in plants were used as natural reducing agents. It has been well known that the different plant compounds such as tannins, flavonoids, anthraquinonoids, terpenoids, and chalcones are have been widely used as reducing and stabilizing agents for the green synthesis of AgNPs with several beneficial properties for textiles.

In this contribution, the aim of the present study was to propose a simple and reliable green method based on plant biomolecule-mediated in situ synthesis to fabricate antifungal textiles enhanced by AgNPs. AgNPs were produced on various textiles fibers by in situ reductions of $\mathrm{AgNO}_{3}$ with the Ageratum conyzoides extract. Next, the treated textiles were tested for the potential application as an antifungal textile. Ageratum conyzoides is categorized as a weed and is commonly found in Indonesia and Malaysia. It basically contains flavonoids and terpenoids that can be potential as the natural reducing agents to reduce $\mathrm{Ag}^{+}$to $\mathrm{Ag}^{0}$ [16].

\section{Materials and Methods}

\subsection{Materials.}

Ageratum conyzoides leaves were collected from the surrounding area of Universiti Teknologi Malaysia, Johor, Malaysia. Whatman filter paper (Whatman, Sigma-Aldrich, USA) was used as a filter for preparing pure leave extracts. Ultrapure water was used for this process. Aspergillus sp. was used as a fungus model obtained from the Faculty of Sciences, Universiti Teknologi Malaysia. $\mathrm{AgNO}_{3}$ (QReC, Auckland, New Zealand) was used as a silver source. A stock solution of $\mathrm{AgNO}_{3} 0.1 \mathrm{M}$ was prepared for this study. Four types of textiles, which are cotton $(\mathrm{C})$, poly-cotton $(\mathrm{PC})$, fiber $(\mathrm{F})$, and silk $(\mathrm{S})$ were used in this study and were obtained from a local shop in Johor, Malaysia. 


\subsection{Preparation of Ageratum conyzoides extracts.}

In this study, fresh leaves (10 g) were used. To remove any impurities, the fresh leaves were washed three times, each using the tap water and ultrapure water. Next, the cleaned leaves were mixed with the $200 \mathrm{~mL}$ ultrapure water in a beaker glass. The mixture was boiled up to $80{ }^{\circ} \mathrm{C}$ for $40 \mathrm{~min}$ before cooling at room temperature. To obtain a pure leaves extract, the mixture was filtered using the filter paper. The pure extracts were then stored at a fridge at a temperature of $7^{\circ} \mathrm{C}$ before further use.

\subsection{Preparation of textiles.}

The textiles were cut in a circle shape, having a diameter of $8 \mathrm{~mm}$. The textiles were rinsed using tap water and ultrapure water three times each. It was then followed by boiling the cleaned textiles for $30 \mathrm{~min}$ for the complete removal of any impurities. After boiling, the textiles were dried in the Memmert oven at $50{ }^{\circ} \mathrm{C}$ for $10 \mathrm{~min}$. To attach AgNPs on textiles, the single textile was soaked in $5 \mathrm{~mL}$ solution of $0.1 \mathrm{M} \mathrm{AgNO}_{3}$ for $30 \mathrm{~min}$ in a beaker glass with stirring at a speed of $100 \mathrm{rpm}$. Then, $5 \mathrm{~mL}$ of Ageratum conyzoides extracts were poured carefully into the mixture. The mixture was then heated at $50{ }^{\circ} \mathrm{C}$ for $30 \mathrm{~min}$. To dry the treated textile, the textile was dried in an oven at $50{ }^{\circ} \mathrm{C}$ for $15 \mathrm{~min}$. The same procedure was carried out for all employed textiles. The four types of antifungal textiles are SA (silk-AgNPs), CA (cotton-AgNPs), FA (fiber-AgNPs), and PCA (polycotton-AgNPs).

\subsection{Surface morphology and elemental composition.}

The surface morphology of the treated textiles was studied using the field emission scanning electron microscopy (FESEM, Zeiss Supra 35VP). The equipment was operated at 5 $\mathrm{kV}$ acceleration voltage with a magnification of $\times 50,000$. The treated textiles were also characterized using scanning electron microscopy (SEM) with an energy-dispersive X-ray spectroscopy attachment (SEM-EDX, Hitachi S-34000N) to determine their elemental composition. It was operated at a voltage of $15 \mathrm{kV}$ and equipped with the Bruker Quantax software.

\subsection{Density test and water absorption investigation.}

For the density test, the diameter of the textiles was measured. The mass of dry textiles before attaching with AgNPs was weighed. Next, the treated textiles were also weighed. The density was estimated by dividing the mass weight with the area of the textiles. The density is presented in the unit of $\mathrm{g} / \mathrm{m}^{2}$. For water absorption investigation, it was estimated from the dry and wet mass of the textiles. For this test, all treated and untreated textiles were used. The treated textiles were first soaked in the ultrapure water for $30 \mathrm{~min}$. Water absorption characteristics for all treated textiles were estimated using the following equation [17]:

$$
W A=\frac{W_{w}-W_{d}}{W_{d}} \times 100 \%
$$

where $W A$ is the water absorption $(\%), W_{d}$ is the initial weight of the textiles before absorption $(\mathrm{g})$, and $W_{w}$ is the weight of the textiles after absorption $(\mathrm{g})$. 
2.6. Antifungal examination and washing durability test.

In the present study, Aspergillus sp. was used for antifungal examination. In the preparation, Aspergillus sp. was placed on the center of the agar surface. The petri dish containing the fungal was incubated for $24 \mathrm{~h}$ to assess the inhibition zone. As a comparison, the inhibition zone of the textiles without the AgNPs treatment was also measured as a control. For the investigation of washing durability, the treated textiles were washed for 1,3 , and 5 cycles rpm for $15 \mathrm{~min}$. After the washing treatment, the inhibition zone was measured. In this investigation, the zone of inhibition is presented in the unit of $\mathrm{mm}$.

\section{Results and Discussion}

\subsection{Surface morphology.}

The surface morphology of the textiles before attaching with AgNPs is shown in Figure 1. It is noted that that the surface of the untreated demonstrated smooth longitudinal fibril structure of the fibers without any contaminating particles on the textile surfaces. The deposition of AgNPs on textiles changes the surface morphology of textiles, as shown in Figure 2. It is established that the properties of AgNPs on textiles are influenced by reducing agents, stabilizers, and textiles types.

In general, the aforementioned observation indicated that AgNPs could be successfully deposited on the textiles. Rough fiber surface can be observed after binding with AgNPs because the deposition of AgNPs may make a modification of the surface morphology of the textile fabrics. The formation of particles and agglomerates in different sizes can be observed because every fabric surface has a unique interaction between AgNPs and textile fiber [18].

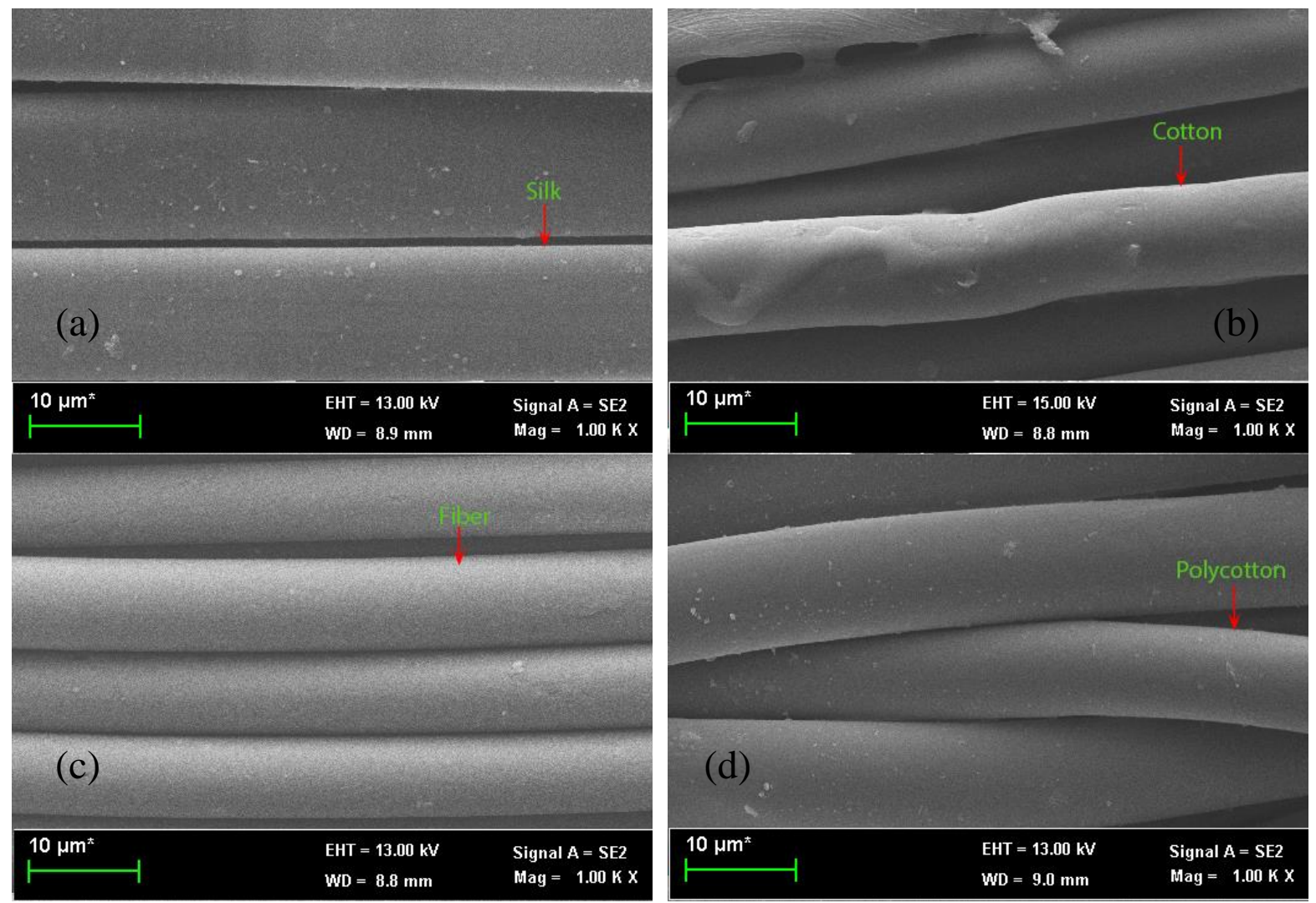

Figure 1. FESEM images for (a) silk, (b) cotton, (c) fiber, and (d) poly-cotton. 


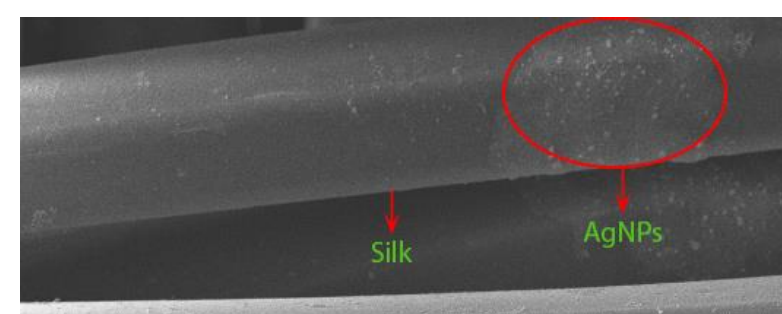

(a)
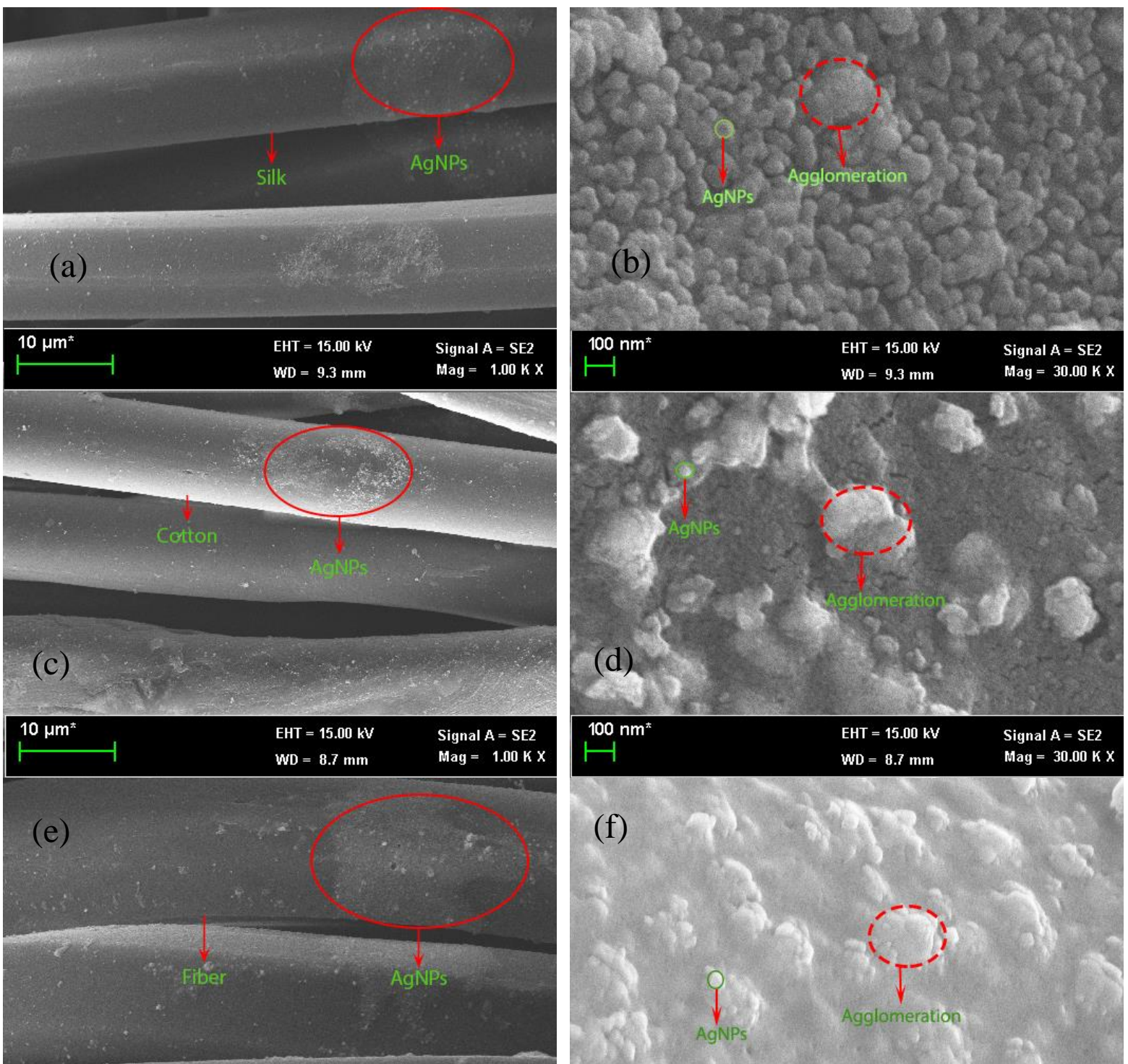

$\begin{array}{lll}10 \mu \mathrm{m}^{\mathrm{*}} & \text { EHT }=15.00 \mathrm{kV} & \text { Signal A }=\text { SE2 } \\ & \text { WD }=9.0 \mathrm{~mm} & \text { Mag }=1.00 \mathrm{KX}\end{array}$
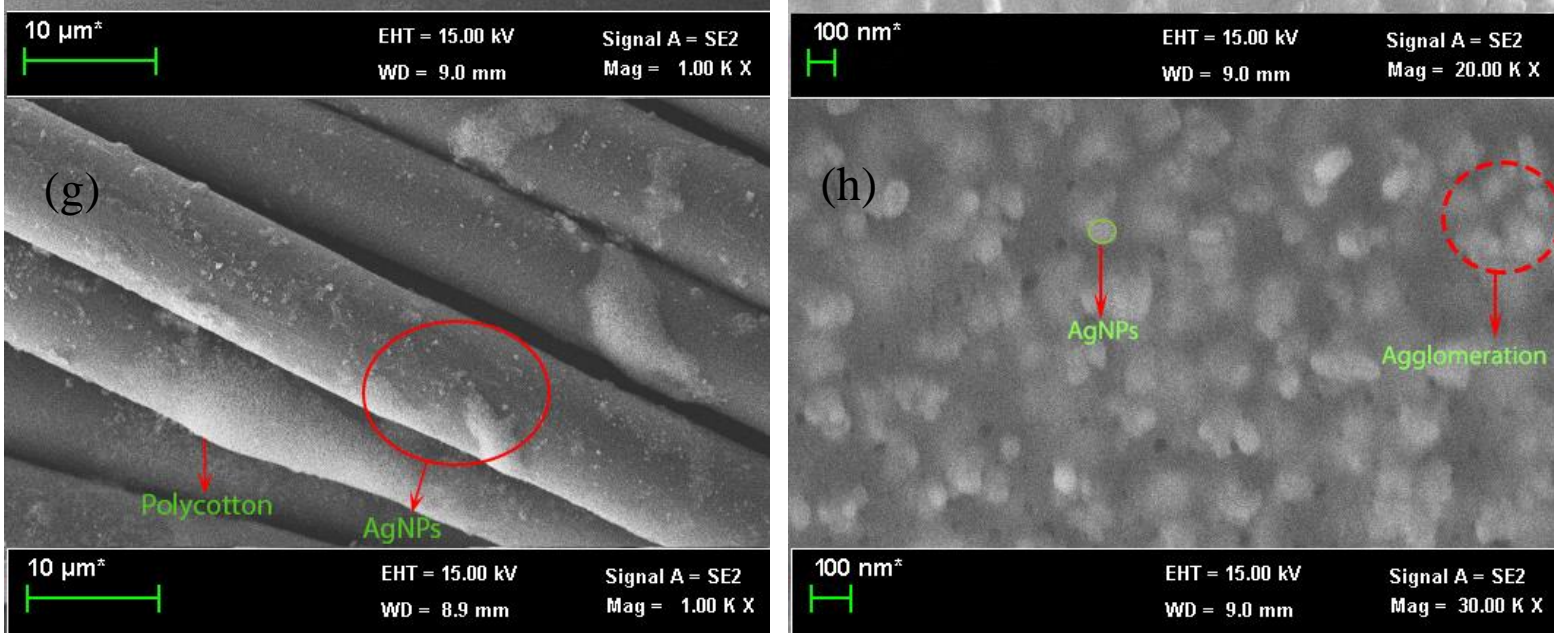

Figure 2. FESEM images of (a-b) SA, (c-d) CA, (e-f) FA, and (g-h) PCA

\subsection{EDX characterization.}

EDX examination was used to determine the elemental composition of textiles before and after attaching with AgNPs. Figure 3 shows the EDX spectra of treated textiles. AgNPs attached to textiles is possibly caused by physical bonding between AgNPs and the textile surface. The physical bonding indicates that AgNPs have temporarily bonding on the textile 
surface. There are some elements detected on the treated textiles, as listed in Table 1. The elements are carbon $(\mathrm{C})$, oxygen $(\mathrm{O})$, nitrogen $(\mathrm{N})$, and silver $(\mathrm{Ag})$. It is noted that $\mathrm{C}$ and $\mathrm{O}$ elements detected possibly came from textile elements. In addition, the $\mathrm{N}$ element detected possibly came from Ageratum conyzoides extracts.

EDX spectra showed the highest peak, approximately $3 \mathrm{keV}$ for all treated textiles, as shown in Figure 3. Similar results were obtained from previous studies with the highest peak observed at $3 \mathrm{keV}$ when AgNPs were synthesized using Ocimum sanctum, Hydrangea paniculate, and Tamarind fruit [19-21]. The peak of approximately $3 \mathrm{keV}$ is attributed as the characteristic of the silver atom, which has an energy level of around $3 \mathrm{keV}$.

Table 1. Elements analysis of all untreated and treated textiles

\begin{tabular}{c|c|c|c} 
Textiles & Elements & Before treated (\%) & After treated (\%) \\
\hline \multirow{4}{*}{ S } & $\mathrm{C}$ & 71.4 & 68.2 \\
\cline { 2 - 4 } & $\mathrm{O}$ & 28.6 & 18.3 \\
\cline { 2 - 4 } & $\mathrm{N}$ & - & 11.3 \\
\cline { 2 - 4 } & $\mathrm{Ag}$ & - & 2.3 \\
\cline { 2 - 4 } & $\mathrm{C}$ & 72.4 & 65.9 \\
\cline { 2 - 4 } & $\mathrm{O}$ & 27.6 & 20.5 \\
\cline { 2 - 4 } & $\mathrm{N}$ & - & 11.7 \\
\hline \multirow{4}{*}{$\mathbf{C}$} & $\mathrm{Ag}$ & - & 1.8 \\
\cline { 2 - 4 } & $\mathrm{C}$ & 72.6 & 45.2 \\
\cline { 2 - 4 } & $\mathrm{O}$ & 27.4 & 20.9 \\
\cline { 2 - 4 } & $\mathrm{N}$ & - & 17.1 \\
\cline { 2 - 4 } & $\mathrm{Ag}$ & - & 60.5 \\
\hline \multirow{4}{*}{$\mathbf{F}$} & $\mathrm{C}$ & 73.8 & 19.3 \\
\cline { 2 - 4 } & $\mathrm{O}$ & 26.2 & 13.4 \\
\cline { 2 - 4 } & $\mathrm{N}$ & - & 6.8
\end{tabular}
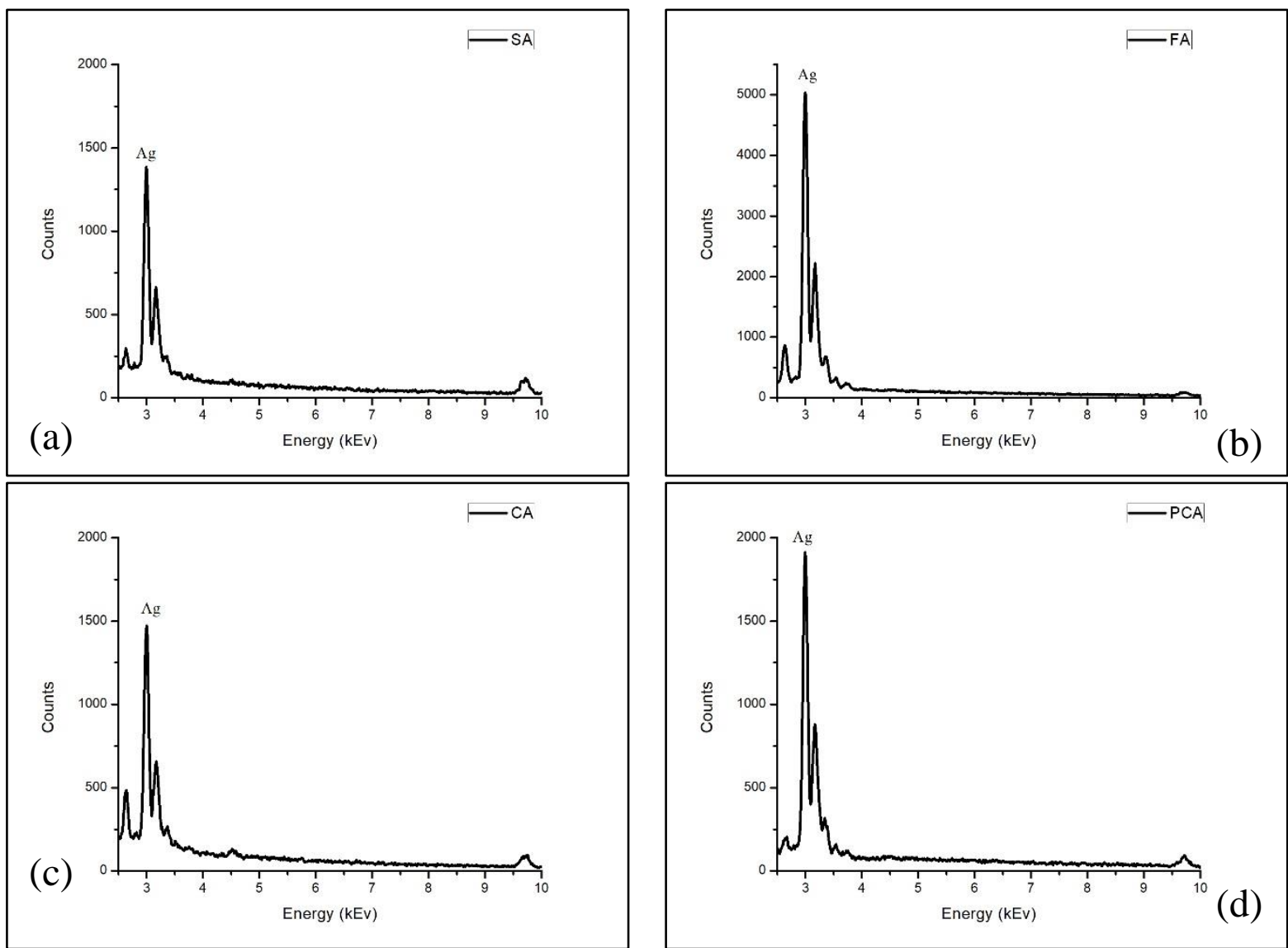

Figure 3. EDX spectra of textiles of (a) SA, (b) CA, (c) FA, and (d) PCA 


\subsection{Density and water absorption.}

Table 2 list the density of untreated and treated textiles. Before treating with AgNPs, cotton, poly-cotton, fiber, and silk had densities by $278.41 \mathrm{~g} / \mathrm{m}^{2}, 119.32 \mathrm{~g} / \mathrm{m}^{2}, 258.52 \mathrm{~g} / \mathrm{m}^{2}$, and $99.43 \mathrm{~g} / \mathrm{m}^{2}$, respectively. After treating with AgNPs, the corresponding values increase up to $556.81 \mathrm{~g} / \mathrm{m}^{2}, 139.20 \mathrm{~g} / \mathrm{m}^{2}, 357.95 \mathrm{~g} / \mathrm{m}^{2}$, and $119.32 \mathrm{~g} / \mathrm{m}^{2}$. It is noted that the deposition of AgNPs on cotton, poly-cotton, fiber, and silk can increase their density by $2.0,1.2,1.4$, and 1.2 times higher compared to untreated textiles.

Table 2. Density of all untreated and treated textiles

\begin{tabular}{c|c} 
Textiles & Density $\left(\mathbf{g} / \mathbf{m}^{\mathbf{2}}\right)$ \\
\hline $\mathbf{S}$ & 99.43 \\
\hline $\mathbf{C}$ & 278.41 \\
\hline $\mathbf{F}$ & 258.52 \\
\hline PC & 119.32 \\
\hline SA & 119.32 \\
\hline CA & 556.81 \\
\hline FA & 357.95 \\
\hline PCA & 139.20
\end{tabular}

Generally, textile density values increase after treating with AgNPs. An increase in density is due to an increase in textile mass after attaching with AgNPs. Table 2 indicates that cotton performed the highest increase in density compared to others. This shows that the mass of cotton increased significantly. An increase in the mass of the cotton indicated that AgNPs could be well attached to cotton. The water absorption test determines the ability of textiles to absorb the water. Table 3 lists the water absorption of untreated and treated textiles. Textiles are made from cellulose, which is easy to absorb water. The textiles have many -OH groups that can bind to water through hydrogen bonds [22]. In general, the percentage of water absorption decreases after the presence of AgNPs.

Table 3. Water absorption of all untreated and treated textiles

\begin{tabular}{c|c} 
Textiles & Water Absorption (\%) \\
\hline S & 92.31 \\
\hline C & 69.57 \\
\hline F & 71.74 \\
\hline PC & 68.42 \\
\hline SA & 89.47 \\
\hline CA & 37.78 \\
\hline FA & 41.94 \\
\hline PCA & 56.25
\end{tabular}

Findings of the present work are in agreement with the previous study, which observed that the treated textiles performed better water resistance compared to the untreated textiles [23]. After dropping water to the treated and untreated textiles, the bulb of water can be formed on their treated textiles surface. In contrast, the water can be perfectly absorbed in untreated textiles. A similar result was also obtained by the previous work, which examined the water absorption of polyester and viscose [17]. Their study reported that the deposition of AgNPs on the textiles could form a barrier between textile fibers and water, which can affect the water absorption characteristics. It is well known that the textile's fiber has a large surface area enabling it to maintain its moisture. Therefore, the deposition of AgNPs on the textile surface can reduce their moisture properties. 


\subsection{Antifungal investigation.}

Table 4 presents the zone of inhibition of the treated textiles against Aspergilus sp. It was found that the treated cotton had a zone of inhibition by $14.67 \pm 3.05 \mathrm{~mm}$. In addition, silk, fiber, and poly-cotton performed zone of inhibition by $12.00 \pm 1.00 \mathrm{~mm}, 15.33 \pm 6.11 \mathrm{~mm}$, and $15.00 \pm 7.81 \mathrm{~mm}$, respectively. In general, the highest zone of inhibition was performed by the treated fiber and followed by poly-cotton, cotton, and silk. The findings of the present study are in line with those of previous studies. AgNPs had a zone of inhibitions by $16.00 \pm 2.00 \mathrm{~mm}$, $20.60 \pm 1.52 \mathrm{~mm}, 19.30 \pm 1.52 \mathrm{~mm}, 11.0 \pm 1.60 \mathrm{~mm}$ when they were tested against Aspergillus niger, Aspergillus fumigatus, and Aspergillus flavus, respectively [24,25]. In addition, photochemical deposition of AgNPs conventional cotton gauzes performed antifungal properties against Candida albicans by up to $5 \mathrm{~mm}$ [26]. By using a simple pad-dry-cure method, cotton fabrics treated with AgNPs also has antifungal properties against different fungal strains Aspergillus fumigatus, Aspergillus niger, Penicillium sp., and Rhizoctonia oryzae [27].

Table 4. zone of inhibition of the treated textiles against Aspergilus sp

\begin{tabular}{c|c} 
Textiles & Inhibition zone $(\mathbf{m m})$ \\
\hline SA & $12.00 \pm 1.00$ \\
\hline CA & $14.67 \pm 3.05$ \\
\hline FA & $15.33 \pm 6.11$ \\
\hline PCA & $15.00 \pm 7.81$
\end{tabular}

It is well established that the antifungal capability of AgNPs depends on their particle properties, procedures, and types of fungi [24,25,28-30]. The current study found that the treated textiles have antifungal properties. These results are likely related to antifungal mechanisms such as by (a) enzyme inactivation, (b) damage DNA replication, (c) disruption of the cell wall, (d) disruption of the cytoplasmic membrane, and (e) preventing the fungal to growth $[31,32]$.

\subsection{Antifungal durability.}

Table 5 presents the inhibition zones of treated textiles after washing the durability test. After washing, the inhibitory zone of the treated textiles decreased. The slight decrease in inhibition zone value is possibly caused by the loss of AgNPs present in textiles after washing treatment. This decrease in inhibition zone indicates that the washing causes reduced antifungal activity on textiles. A previous study showed that antimicrobial reduction was smaller after washing [33-35]. The loss of AgNPS in textiles indicates that there is a physical bonding between AgNPs and textiles. The physical bonding is possibly caused by van der Wals force [36]. The van der Waals bonding has a weak bonding force. The weak bonding force possibility allows AgNPs to be easily released after washing. In general, findings from this study exhibited that the AgNPs showed antimicrobial properties, which supported previous findings reported elsewhere [37-41].

Table 5. Inhibition zones of all treated textiles

\begin{tabular}{c|c|c|c|c}
\multirow{2}{*}{ Textiles } & \multicolumn{4}{|c}{ Inhibition zone (mm) } \\
\cline { 2 - 5 } & \multicolumn{3}{|c}{ Washing cycles } \\
\cline { 2 - 5 } & Without washing & 1 time & 3 times & 5 times \\
\hline SA & 12.00 & 11.00 & 10.00 & 9.00 \\
\hline CA & 15.00 & 12.00 & 11.00 & 10.00 \\
\hline FA & 15.33 & 12.00 & 11.00 & 10.00 \\
\hline PCA & 15.00 & 12.00 & 11.00 & 10.00
\end{tabular}




\section{Conclusions}

The aim of this study was to propose a green method for the enhancement of antifungal of textiles using AgNPs. This study found that AgNPs can be successfully deposited on the various textiles. Generally, the current study established that the treated textiles with AgNPs had antifungal ability depending on textile types. The surface bonding AgNPs on textile was possibly caused by van der Waals force. Moreover, all treated textiles demonstrated antifungal activity, although after 5 washing cycles.

\section{Funding}

This study was supported by the Institut Teknologi Sepuluh Nopember under the International Cooperation Research Grant (ICRG), grant number 1171/PKS/ITS/2019.

\section{Acknowledgments}

The authors also thank the Universiti Teknologi Malaysia for facilitating this work.

\section{Conflicts of Interest}

\section{The authors declare no conflict of interest}

\section{References}

1. Naik, R.R.; Stringer, S.J.; Agarwal, G.; Jones, S.E.; Stone, M.O. Biomimetic synthesis and patterning of silver nanoparticles. Nature Materials 2002, 1, 169-172, http://dx.doi.org/10.1038/nmat758.

2. Park, M.; Im, J.; Shin, M.; Min, Y.; Park, J.; Cho, H.; Park, S.; Shim, M.B.; Jeon, S.; Chung, D.Y.; Bae, J.; Park, J.; Jeong, U.; Kim, K. Highly stretchable electric circuits from a composite material of silver nanoparticles and elastomeric fibres. Nature Nanotechnology 2012, 7, 803-809, https://doi.org/10.1038/nnano.2012.206.

3. Syafiuddin, A.; Salmiati, S.; Hadibarata, T.; Kueh, A.B.H.; Salim, M.R. Novel weed-extracted silver nanoparticles and their antibacterial appraisal against a rare bacterium from river and sewage treatment plan. Nanomaterials 2018, 8, 1-17, https://doi.org/10.3390/nano8010009.

4. Syafiuddin, A.; Salmiati, S.; Hadibarata, T.; Kueh, A.B.H.; Salim, M.R.; Zaini, M.A.A. Silver nanoparticles in the water environment in Malaysia: Inspection, characterization, removal, modeling, and future perspective. Scientific Reports 2018, 8, 1-15, https://doi.org/10.1038/s41598-018-19375-1.

5. Syafiuddin, A.; Salmiati, S.; Hadibarata, T.; Salim, M.R.; Kueh, A.B.H.; Suhartono, S. Removal of silver nanoparticles from water environment: Experimental, mathematical formulation, and cost analysis. Water, Air, and Soil Pollution 2019, 230, 102-117, https://doi.org/10.1007/s11270-019-4143-8.

6. Syafiuddin, A.; Fulazzaky, M.A.; Salmiati, S.; Kueh, A.B.H.; Fulazzaky, M.; Salim, M.R. Silver nanoparticles adsorption by the synthetic and natural adsorbent materials: an exclusive review. Nanotechnology for Environmental Engineering 2020, 5, 1-18, https://doi.org/10.1007/s41204-019-0065-3.

7. Syafiuddin, A.; Salmiati, S.; Jonbi, J.; Fulazzaky, M.A. Application of the kinetic and isotherm models for better understanding of the behaviors of silver nanoparticles adsorption onto different adsorbents. Journal of Environmental Management 2018, 218, 59-70, https://doi.org/10.1016/j.jenvman.2018.03.066.

8. Syafiuddin, A. Toward a comprehensive understanding of textiles functionalized with silver nanoparticles. Journal of the Chinese Chemical Society 2019, 66, 793-814, https://doi.org/10.1002/jccs.201800474.

9. Bagherzade, G.; Tavakoli, M.M.; Namaei, M.H. Green synthesis of silver nanoparticles using aqueous extract of saffron (Crocus sativus L.) wastages and its antibacterial activity against six bacteria. Asian Pacific Journal of Tropical Biomedicine 2017, 7, 227-233, http://dx.doi.org/10.1016/j.apjtb.2016.12.014.

10. Khalil, M.M.H.; Ismail, E.H.; El-Baghdady, K.Z.; Mohamed, D. Green synthesis of silver nanoparticles using olive leaf extract and its antibacterial activity. Arabian Journal of Chemistry 2014, 7, 1131-1139, http://dx.doi.org/10.1016/j.arabjc.2013.04.007.

11. Lee, K.J.; Park, S.H.; Govarthanan, M.; Hwang, P.H.; Seo, Y.S.; Cho, M.; Lee, W.H.; Lee, J.Y.; KamalaKannan, S.; Oh, B.T. Synthesis of silver nanoparticles using cow milk and their antifungal activity against phytopathogens. Materials Letters 2013, 105, 128-131, https://doi.org/10.1016/j.matlet.2013.04.076.

12. Syafiuddin, A.; Salmiati, S.; Hadibarata, T.; Salim, M.R.; Kueh, A.B.H.; Sari, A.A. A purely green synthesis of silver nanoparticles using Carica papaya, Manihot esculenta, and Morinda citrifolia: Synthesis and 
antibacterial evaluations. Bioprocess and Biosystems Engineering 2017, 40, 1349-1361, https://doi.org/10.1007/s00449-017-1793-z.

13. Shateri-Khalilabad, M.; Yazdanshenas, M.E.; Etemadifar, A. Fabricating multifunctional silver nanoparticles-coated cotton fabric. Arabian Journal of Chemistry 2017, 10, S2355-S2362, https://doi.org/10.1016/j.arabjc.2013.08.013.

14. Dubas, S.T.; Kumlangdudsana, P.; Potiyaraj, P. Layer-by-layer deposition of antimicrobial silver nanoparticles on textile fibers. Colloids and Surfaces A: Physicochemical and Engineering Aspects 2006, 289, 105-109, https://doi.org/10.1016/j.colsurfa.2006.04.012.

15. Perelshtein, I.; Applerot, G.; Perkas, N.; Guibert, G.; Mikhailov, S.; Gedanken, A. Sonochemical coating of silver nanoparticles on textile fabrics (nylon, polyester and cotton) and their antibacterial activity. Nanotechnology 2008, 19, 1-7.

16. Kasali, A.A.; Winterhalter, P.; Adio, A.M.; Knapp, H.; Bonnlander, B. Chromenes in Ageratum conyzoides L. Flavour and Fragrance Journal 2002, 17, 247-250, https://doi.org/10.1002/ffj.1099.

17. Erdem, R.; Rajendran, S. Influence of silver loaded antibacterial agent on knitted and nonwoven fabrics and some fabric properties. Journal of Engineered Fabrics and Fibers 2016, 11, 38-46, https://doi.org/10.1177\%2F155892501601100107.

18. Mahmud, S.; Sultana, M.Z.; Pervez, M.N.; Habib, M.A.; Liu, H.H. Surface functionalization of "Rajshahi Silk" using green silver nanoparticles. Fibers 2017, 5, 35-52, https://doi.org/10.3390/fib5030035.

19. Subba Rao, Y.; Kotakadi, V.S.; Prasad, T.N.V.K.V.; Reddy, A.V.; Sai Gopal, D.V.R. Green synthesis and spectral characterization of silver nanoparticles from Lakshmi tulasi (Ocimum sanctum) leaf extract. Spectrochimica Acta Part A: Molecular and Biomolecular Spectroscopy 2013, 103, 156-159, https://doi.org/10.1016/j.saa.2012.11.028.

20. Karunakaran, G.; Jagathambal, M.; Venkatesh, M.; Suresh Kumar, G.; Kolesnikov, E.; Dmitry, A.; Gusev, A.; Kuznetsov, D. Hydrangea paniculata flower extract-mediated green synthesis of MgNPs and AgNPs for health care applications. Powder Technology 2017, 305, 488-494, https://doi.org/10.1016/j.powtec.2016.10.034.

21. Jayaprakash, N.; Vijaya, J.J.; Kaviyarasu, K.; Kombaiah, K.; Kennedy, L.J.; Ramalingam, R.J.; Munusamy, M.A.; Al-Lohedan, H.A. Green synthesis of Ag nanoparticles using Tamarind fruit extract for the antibacterial studies. Journal of Photochemistry and Photobiology B: Biology 2017, 169, 178-185, https://doi.org/10.1016/j.jphotobiol.2017.03.013.

22. Tzanov, T.; Calafell, M.; Guebitz, G.M.; Cavaco-Paulo, A. Bio-preparation of cotton fabrics. Enzyme and Microbial Technology 2001, 29, 357-362, https://doi.org/10.1016/S0141-0229(01)00388-X.

23. Xing, Y.; Yang, X.; Dai, J. Antimicrobial finishing of cotton textile based on water glass by sol-gel method. Journal of Sol-Gel Science and Technology 2007, 43, 187-192, https://doi.org/10.1007/s10971-007-1575-1.

24. Balashanmugam, P.; Balakumaran, M.D.; Murugan, R.; Dhanapal, K.; Kalaichelvan, P.T. Phytogenic synthesis of silver nanoparticles, optimization and evaluation of in vitro antifungal activity against human and plant pathogens. Microbiological Research 2016, 192, 52-64, https://doi.org/10.1016/j.micres.2016.06.004.

25. Bocate, K.P.; Reis, G.F.; de Souza, P.C.; Oliveira Junior, A.G.; Durán, N.; Nakazato, G.; Furlaneto, M.C.; de Almeida, R.S.; Panagio, L.A. Antifungal activity of silver nanoparticles and simvastatin against toxigenic species of Aspergillus. International Journal of Food Microbiology 2019, 291, 79-86, https://doi.org/10.1016/j.ijfoodmicro.2018.11.012.

26. Paladini, F.; De Simone, S.; Sannino, A.; Pollini, M. Antibacterial and antifungal dressings obtained by photochemical deposition of silver nanoparticles. Journal of Applied Polymer Science 2014, 131, 1-8, http://dx.doi.org/10.1002/app.40326.

27. Balakumaran, M.D.; Ramachandran, R.; Jagadeeswari, S.; Kalaichelvan, P.T. In vitro biological properties and characterization of nanosilver coated cotton fabrics - An application for antimicrobial textile finishing. International Biodeterioration \& Biodegradation $\quad \mathbf{2 0 1 6}, \quad 107, \quad 48-55$, https://doi.org/10.1016/j.ibiod.2015.11.011.

28. Tutaj, K.; Szlazak, R.; Szalapata, K.; Starzyk, J.; Luchowski, R.; Grudzinski, W.; Osinska-Jaroszuk, M.; Jarosz-Wilkolazka, A.; Szuster-Ciesielska, A.; Gruszecki, W.I. Amphotericin B-silver hybrid nanoparticles: synthesis, properties and antifungal activity. Nanomedicine: Nanotechnology, Biology and Medicine 2016, 12, 1095-1103, https://doi.org/10.1016/j.nano.2015.12.378.

29. Fernández, J.G.; Fernández-Baldo, M.A.; Berni, E.; Camí, G.; Durán, N.; Raba, J.; Sanz, M.I. Production of silver nanoparticles using yeasts and evaluation of their antifungal activity against phytopathogenic fungi. Process Biochemistry 2016, 51, 1306-1313, https://doi.org/10.1016/j.procbio.2016.05.021.

30. Kumar, S.V.; Bafana, A.P.; Pawar, P.; Rahman, A.; Dahoumane, S.A.; Jeffryes, C.S. High conversion synthesis of $<10 \mathrm{~nm}$ starch-stabilized silver nanoparticles using microwave technology. Scientific Reports 2018, 8, http://dx.doi.org/10.1038/s41598-018-23480-6.

31. Panáček, A.; Kolář, M.; Večeřová, R.; Prucek, R.; Soukupová, J.; Kryštof, V.; Hamal, P.; Zbořil, R.; Kvítek, L. Antifungal activity of silver nanoparticles against Candida spp. Biomaterials, 2009. 30, 6333-6340, http://dx.doi.org/10.1016/j.biomaterials.2009.07.065. 
32. Azizi, Z.; Pourseyedi, S.; Khatami, M.; Mohammadi, H. Stachys lavandulifolia and Lathyrus sp. mediated for green synthesis of silver nanoparticles and evaluation its antifungal activity against Dothiorella sarmentorum. Journal of Cluster Science 2016, 27, 1613-1628, https://doi.org/10.1007/s10876-016-1024-9.

33. Zhou, Q.; Lv, J.; Ren, Y.; Chen, J.; Gao, D.; Lu, Z.; Wang, C. A green in situ synthesis of silver nanoparticles on cotton fabrics using Aloe vera leaf extraction for durable ultraviolet protection and antibacterial activity. Textile Research Journal 2017, 87, 2407-2419, https://doi.org/10.1177\%2F0040517516671124.

34. Shahid, M.; Zhou, Y.; Cheng, X.W.; Zar, M.S.; Chen, G.; Tang, R.C. Ferulic acid promoted in-situ generation of AgNPs@silk as functional colorants. Journal of Cleaner Production 2018, 176, 736-744, https://doi.org/10.1016/j.jclepro.2017.12.171.

35. Ibrahim, N.A.; El-Zairy, E.M.; Eid, B.M.; Emam, E.; Barkat, S.R. A new approach for imparting durable multifunctional properties to linen-containing fabrics. Carbohydrate Polymers 2017, 157, 1085-1093, https://doi.org/10.1016/j.carbpol.2016.10.074.

36. Syafiuddin, A.; Salmiati; Salim, M.R.; Kueh, A.B.H.; Hadibarata, T.; Nur, H. A review of silver nanoparticles: Research trends, global consumption, synthesis, properties, and future challenges. Journal of the Chinese Chemical Society 2017, 64, 732-756, https://doi.org/10.1002/jccs.201700067.

37. Fadlilah, D.R.; Endarko, E.; Ratnasari, A.; Hozairi, H.; Yusop, Z.; Syafiuddin, A., Enhancement of antibacterial properties of various polymers functionalized with silver nanoparticles. Biointerface Research in Applied Chemistry, 2020. 10, 5592-5598, https://doi.org/10.33263/BRIAC0103.592598.

38. Fajar, M.N.; Endarko, E.; Rubiyanto, A.; Malek, N.A.N.N.; Hadibarata, T.; Syafiuddin, A., A green deposition method of silver nanoparticles on textiles and their antifungal activity. Biointerface Research in Applied Chemistry, 2020. 10, 4902-4907, https://doi.org/10.33263/BRIAC101.902907.

39. Murugan, N.; Natarajan, D., Bionanomedicine for antimicrobial therapy - a case study from Glycosmis pentaphylla plant mediated silver nanoparticles for control of multidrug resistant bacteria. Letters in Applied NanoBioScience, 2018. 7, 523-540, https://doi.org/10.33263/LIANBS834.523540.

40. Pathak, J.; Sonker, A.S.; Rajneesh; Singh, V.; Kumar, D.; Sinha, R.P., Synthesis of silver nanoparticles from extracts of Scytonema geitleri HKAR-12 and their in vitro antibacterial and antitumor potentials. Letters in Applied NanoBioScience, 2019. 8, 576-585, https://doi.org/10.33263/LIANBS83.576585.

41. Nurul Aini, A.; Al Farraj, D.A.; Endarko, E.; Rubiyanto, A.; Nur, H.; Al Khulaifi, M.M.; Hadibarata, T.; Syafiuddin, A., A new green method for the synthesis of silver nanoparticles and their antibacterial activities against gram-positive and gram-negative bacteria. Journal of the Chinese Chemical Society, 2019. 66, 705712, https://doi.org/10.1002/jccs.201800412. 